\title{
Numerical model for the uptake of groundwater contaminants by phreatophytes
}

\author{
M. A. Widdowson ${ }^{1}$, A. El-Sayed ${ }^{1} \&$ J. E. Landmeyer ${ }^{2}$ \\ ${ }^{I}$ The Charles E. Via, Jr., \\ Department of Civil and Environmental Engineering, Virginia Tech, USA \\ ${ }^{2}$ U.S. Geological Survey, USA
}

\begin{abstract}
Conventional solute transport models do not adequately account for the effects of phreatophytic plant systems on contaminant concentrations in shallow groundwater systems. A numerical model was developed and tested to simulate threedimensional reactive solute transport in a heterogeneous porous medium. Advective-dispersive transport is coupled to biodegradation, sorption, and plantbased attenuation processes including plant uptake and sorption by plant roots. The latter effects are a function of the physical-chemical properties of the individual solutes and plant species. Models for plant uptake were tested and evaluated using the experimental data collected at a field site comprised of hybrid poplar trees. A non-linear equilibrium isotherm model best represented site conditions.

Keywords: phytoremediation, plant uptake, volatile organic compounds, solute transport, groundwater.
\end{abstract}

\section{Introduction}

Phytoremediation is the use of plants to remediate contamination in soil and groundwater. Engineered phytoremediation systems have served as the primary remedial strategy at some sites, but it is more common for plants to be used in combination with other technologies as a polishing step. The initial application of phytoremediation was the use of hyperaccumulator plants to extract and accumulate toxic heavy metals from surface soils. Since then, a number of mechanisms have been shown to remove or degrade volatile organic compounds (VOC), such as trichloroethene (TCE), during phytoremediation. Plant-based 
mechanisms applicable to VOCs include rhizosphere biodegradation, hydraulic control, root sorption, and direct uptake and translocation combined with enzymatic phytotransformation and/or phytovolatilization [1].

Phreatophytes are known to be effective in controlling and treating VOCs in groundwater systems. Trees, such as poplars, willows, and cottonwoods, can develop long root systems to draw water from the upper saturated zone and capillary fringe. In particular, hybrid poplar varieties are fast-growers, perennial, long-lived (25-50 years) and tolerant of organic contamination [2]. Poplar trees can transpire 100 to $200 \mathrm{~L} /$ day under optimal conditions [3]. Phreatophytes are used to control groundwater movement during the growing season by reduction of recharge and the Darcy flux through leaf-canopy interception of precipitation and through direct transpiration, respectively. The latter facilitates direct uptake of VOCs into roots and the plant xylem. Phytoremediation mechanisms can be plant-specific but will depend on the physical-chemical properties of the compound [4].

Presently, numerical models for solute transport in the saturated zone have not adequately incorporated the effects of phreatophytes on the fate and transport of VOCs. In this research, mathematical and computational models are developed to simulate mass removal from groundwater systems through plant uptake. Field-based methods to quantify phytovolatilization and direct transpiration are utilized in the development and testing of the model. Fieldscale simulations are presented to illustrate the utility of the computational model for predicting the effects of a poplar-based phytoremediation system on an aqueous VOC plume.

\section{Mathematical model}

The equation of mass balance for the VOC concentration $\left(C_{l}\right)$ of the species $l$ in the mobile aqueous phase may be expressed as:

$$
-\frac{\partial}{\partial x_{i}}\left(\theta v_{i} C_{l}\right)+\frac{\partial}{\partial x_{i}}\left(\theta D_{i j} \frac{\partial C_{l}}{\partial x_{j}}\right)+R_{\text {source } \sin k, l}-q_{E T} C_{l}^{T}=\theta R_{l} \frac{\partial C_{l}}{\partial t}
$$

where $\theta=$ aquifer porosity $\left[\mathrm{L}^{\circ}\right] ; x_{i}=$ distance $[\mathrm{L}] ; t=$ time $[\mathrm{T}] ; v_{i}=$ average ground-water velocity $\left[\mathrm{L} \mathrm{T}^{-1}\right] ; D_{i j}=$ tensor for the hydrodynamic dispersion coefficient $\left[\mathrm{L}^{2} \mathrm{~T}^{-1}\right] ; R_{\text {source } / \sin k, l}=$ mass source-sink term for reactions and mass transfer $\left[\mathrm{M} \mathrm{L}^{-3} \mathrm{~T}^{-1}\right]$; and $R_{l}$ is the retardation factor for the sorption associated with aquifer sediment. The term $q_{E T} C_{l}^{T}$ accounts for mass removal through plant uptake where $q_{E T}=$ areally-distributed fluid sink for direct transpiration from the saturated zone (volumetric flow rate per unit volume of aquifer) $\left[\mathrm{T}^{-1}\right]$; and $C_{l}^{T}=$ VOC concentration associated with the transpiration stream $\left[\mathrm{M} \mathrm{L}^{-3}\right]$. Generally, plants translocate water and dissolved substances through their vascular bundles, which are mostly comprised of xylem and phloem. 


\subsection{Direct uptake - linear equilibrium model}

Burken and Schnoor [4] and others developed an equilibrium model based on laboratory-scale experiments in which the transpiration stream concentration is expressed as the product of TSCF and the solute concentration in the pore water. Using the linear equilibrium model, Equation (1) may be expressed as

$$
-\frac{\partial}{\partial x_{i}}\left(\theta v_{i} C_{l}\right)+\frac{\partial}{\partial x_{i}}\left(\theta D_{i j} \frac{\partial C_{l}}{\partial x_{j}}\right)+R_{\text {source } \sin k, l}-q_{E T} \tau_{l} C_{l}=\theta R_{l} \frac{\partial C_{l}}{\partial t}
$$

TSCF values are derived through laboratory experiments using a specific compound and plant species of interest or empirical equations that express TSCF as function of the octanol/water partition coefficient $\left(K_{o w}\right)$ of a compound. For example, Burken and Schnoor [4] presented an expression for the TSCF of twelve organic compounds commonly found at hazardous waste sites using experimental data from hydroponic poplar trees experiments:

$$
(T S C F)=0.784 \times \exp \left[-\frac{\left(\log K_{o w}-1.78\right)^{2}}{2.44}\right]
$$

Until now, the TSCF concept has been limited in terms of implementation in solute transport models. However, it has been observed that the TSCF concept does not account for losses within the tree and caution should be exercised when selecting TSCF values for compounds that are known to degrade metabolically in the transpiration stream of plants (e.g. atrazine) [4].

\subsection{Direct uptake - non-linear equilibrium model}

Field measurement of phytovolatilization at contaminated sites has shown a correlation between VOC transpiration concentrations observed in tree tissue and VOC concentrations measured in groundwater [5,6]. Regression of field data at a solvent-contaminated site suggests that alternative models for plant uptake may be more appropriate and less constraining to simulate the contaminant fate in a phytoremediation system relative to the linear model [7]. In this case, regression analysis was performed between VOC transpiration concentration data collected from xylem in tree trunks and both soil and groundwater VOC concentration data to yield:

$$
C^{T}=(T S C F) \times C^{N}
$$

where $\mathrm{N}=$ empirical exponent. Equation (4) provides a more robust approach to simulating plant uptake in the solute transport equation:

$$
-\frac{\partial}{\partial x_{i}}\left(\theta v_{i} C_{l}\right)+\frac{\partial}{\partial x_{i}}\left(\theta D_{i j} \frac{\partial C_{l}}{\partial x_{j}}\right)+R_{\text {source } / \sin k, l}-q_{E T} \tau_{l} C_{l}^{N}=\theta R_{l} \frac{\partial C_{l}}{\partial t}
$$

but requires site-specific data collected from each plant species contributing to direct transpiration and uptake. 


\subsection{Direct uptake - plant concentration capacity}

Laboratory experiments suggest that phreatophytes have a specific maximum tolerance to dissolved contaminants due to toxicity effects. For example, Dietz and Schnoor [8] tested a series of nine chlorinated aliphatic compounds for phytotoxicity to hybrid poplar (Populus deltoids $\times$ Populus nigra 'DN34') plantings. Highly chlorinated aliphatic compounds were more toxic to poplar cuttings than compounds with fewer chlorine atoms within the set of five chlorinated ethenes and four chlorinated ethanes tested [8]. To account for the effect concentration-limited uptake, the Langmuir isotherm is adapted as follows

$$
C_{i}^{T}=\frac{K_{1} \times T_{c} C_{i}}{1+K_{1} C_{i}}
$$

where $K_{l}\left[\mathrm{~L}^{3} \mathrm{M}^{-1}\right]$ and $T_{c}\left[\mathrm{M} \mathrm{L}^{-3}\right]$ are constants dependent on the compound and the susceptibility of the plant to toxicity effects. Substitution into Equation (1) yields:

$$
-\frac{\partial}{\partial x_{i}}\left(\theta v_{i} C_{l}\right)+\frac{\partial}{\partial x_{i}}\left(\theta D_{i j} \frac{\partial C_{l}}{\partial x_{j}}\right)+R_{\text {source } / \sin k, l}-\left(\frac{K_{1} \times T_{c} C_{i}}{1+K_{1} C_{i}}\right) q_{E T}=\theta R_{l} \frac{\partial C_{l}}{\partial t}
$$

At low concentrations, $K_{l} C_{l}<<1$, the model is linear (Eq. 2), and $K_{1} \times T_{c}=\tau_{1}$. At relatively large groundwater concentrations where $K_{l} C_{l} \gg 1$, the model reaches a constant value, so that $C_{l}^{T}=T_{c}$.

\section{Model implementation and testing}

The model for plant uptake coupled to solute transport was implemented using the code SEAM3D (Sequential Electron Acceptor Model, 3D Transport) [9,10]. SEAM3D is modular code designed to solve fully three-dimensional reactive transport problems in heterogeneous, anisotropic aquifers. It is a companion code to MODFLOW, a code for solving groundwater flow problems using a finite difference cell-centered grid. The SEAM3D Plant Uptake Package (PUP) was tested and verified by comparing results to the Source Sink Mixing (SSM) Package for the test case where TSCF $=1.0$. Both closed and open system test problems were verified against results using the SSM module.

Time-dependent test cases were devised so that concentration changes depended solely on plant uptake. In each case, the model domain represented a $100-\mathrm{m} \times 100-\mathrm{m} \times 10-\mathrm{m}$ unconfined aquifer, divided into 100 cells of uniform dimensions. In generating the groundwater flow field, the water table was horizontal $(\mathrm{h}=8.0 \mathrm{~m})$, so that the Darcy flux in each cell was zero in the transport simulations. The starting concentration of the single solute model was uniform $(10 \mathrm{mg} / \mathrm{L})$, and rates of transpiration and recharge $(0.01 \mathrm{~m} / \mathrm{d})$ were identical at all nodes, forcing the concentration gradients to be zero.

Fig. 1 shows the model domain for the closed system test problem. Simulation results in fig. 2 show dissolved mass removed through plant uptake versus time. The linear model was verified by comparing both concentration and 
mass removed simulated using the SSM Package in SEAM3D for TSCF $=1.0$. The problem was repeated to investigate the effect of the input parameter TSCF on mass uptake versus time. As the TSCF decreases, the mass of the solute taken by the plant decreases compared with mass uptake for TSCF $=1.0$.

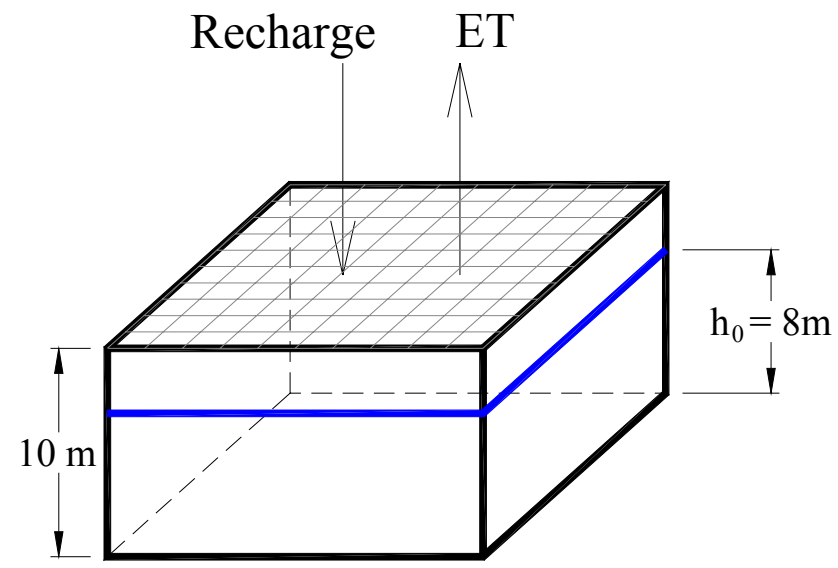

Figure 1: Schematic of a closed system problem domain for testing the direct uptake models.

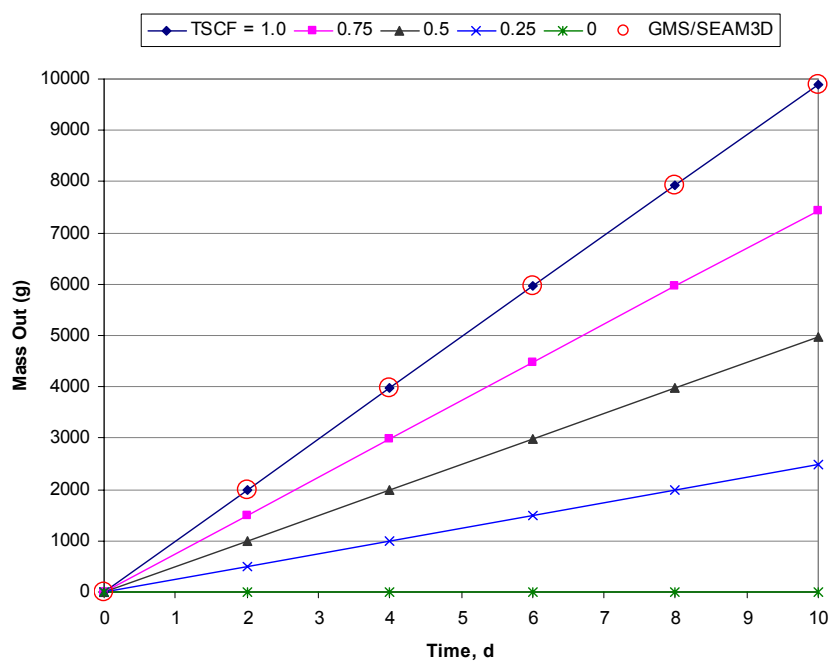

Figure 2: $\quad$ Simulated mass removed by plant uptake versus time using the linear model in the closed-system problem domain (fig. 1) for values of TSCF varying from 0 to 1.0. The results show an identical match with an existing model where TSCF $=1.0$. 


\section{Phytoremediation problem}

To demonstrate the utility of the code and compare the different models for plant uptake, several simulations were performed using an open model domain. The model domain dimensions were $1500 \mathrm{~m}$ by $500 \mathrm{~m}$ with a $10-\mathrm{m}$ thickness and a uniform cell size of $5 \mathrm{~m}$ by $5 \mathrm{~m}$. The input flow rate $\left(1.5 \mathrm{~m}^{3} / \mathrm{d} /\right.$ cell $)$ was constant to the system at the left boundary with a total inflow rate $=150 \mathrm{~m}^{3} /$ day. Table 1 lists the input parameter for the model simulations.

Table 1: $\quad$ Model parameters.

\begin{tabular}{|c|c|}
\hline Parameter & Value \\
\hline Hydraulic conductivity & $187 \mathrm{~m} / \mathrm{d}$ \\
\hline Horizontal anisotropy & 1.0 \\
\hline Maximum transpiration rate & $0.001 \mathrm{~m}^{3} / \mathrm{d} / \mathrm{m}^{2}$ \\
\hline Root extinction depth & $4.0 \mathrm{~m}$ \\
\hline Ground surface elevation & $5.0 \mathrm{~m}$ \\
\hline Constant head boundary & $5.25 \mathrm{~m}$ \\
\hline Model thickness (one layer) & $10.0 \mathrm{~m}$ \\
\hline Porosity & 0.25 \\
\hline Longitudinal dispersivity & $10.0 \mathrm{~m}$ \\
\hline Dispersivity ratio & 0.2 \\
\hline First order decay rate & $0.0011 / \mathrm{d}$ \\
\hline Number of stress periods & 20 \\
\hline Stress period length & $182.5 \mathrm{~d}$ \\
\hline
\end{tabular}

\subsection{Linear plant uptake model}

As shown in fig. 3 (top), the plume reaches a steady-state under natural attenuation conditions without the influence of phytoremediation. The concentration results at the end of this simulation serve as the initial concentrations in the phytoremediation model. The area covered by poplar trees was variable with the maximum dimensions selected to cover the areal extent of the steady-state VOC plume. In this case, the length $\left(\mathrm{L}_{\mathrm{ET}}\right)$ and width $\left(\mathrm{W}_{\mathrm{ET}}\right)$ of the phytoremediation are half of the plume length $\left(\mathrm{L}_{\mathrm{p}}\right)$ and three times greater than the source width $\left(\mathrm{W}_{\mathrm{P}}\right)$, respectively. The concentration profile in fig. 3 (bottom) shows that the plume length decreases due to plant uptake. The sensitivity of plume concentration to the range of TSCF values is also demonstrated. As expected, as the TSCF increases, greater solute mass removal occurs, decreasing the VOC concentrations. It is also noticeable that the concentration profiles for different values of TSCF tend to gather in one line after a certain distance downstream the source in the case of $\mathrm{L}_{\mathrm{ET}}=0.5 \mathrm{~L}_{\mathrm{p}}$. This leads to the conclusion that TSCF will have minimal effect of the concentration after a certain distance downstream the source. 


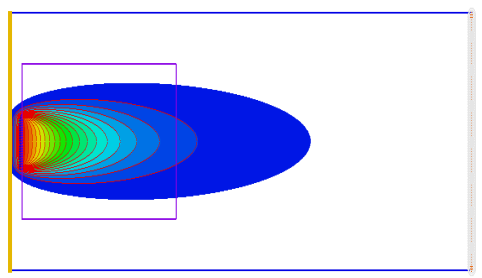

*Phytoremediation - IC

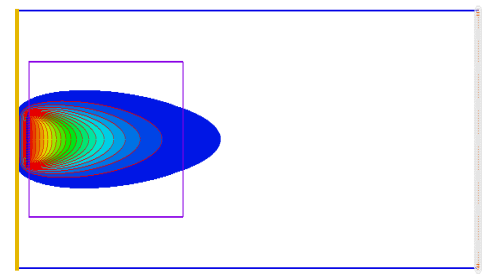

Phytoremediation - End

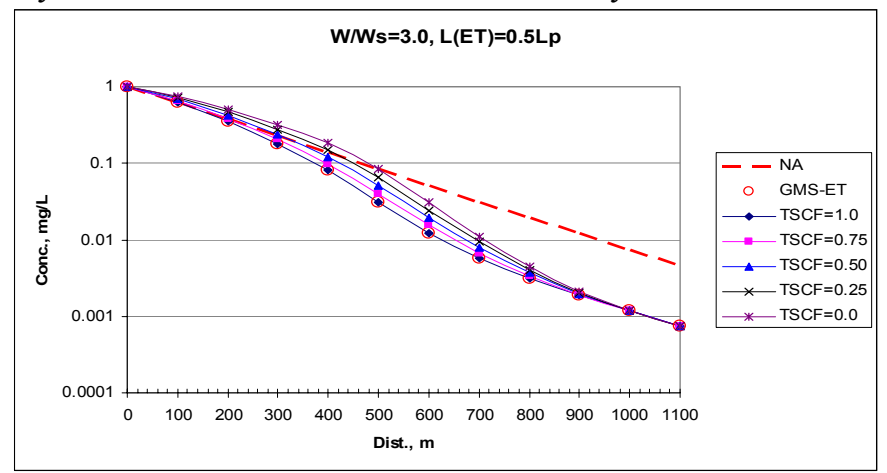

Figure 3: $\quad$ VOC plume simulation results for natural attenuation (top left), which serve as initial conditions (IC) for the phytoremediation problem. Steady-state plume results for the phytoremediation systems (top right) are shown for the case where the poplar trees are planted over the plume, resulting in contraction and restabilization of the plume over time. Concentration profiles for the phytoremediation-based results are shown for values of TSCF varying from 0 to 1.0 .

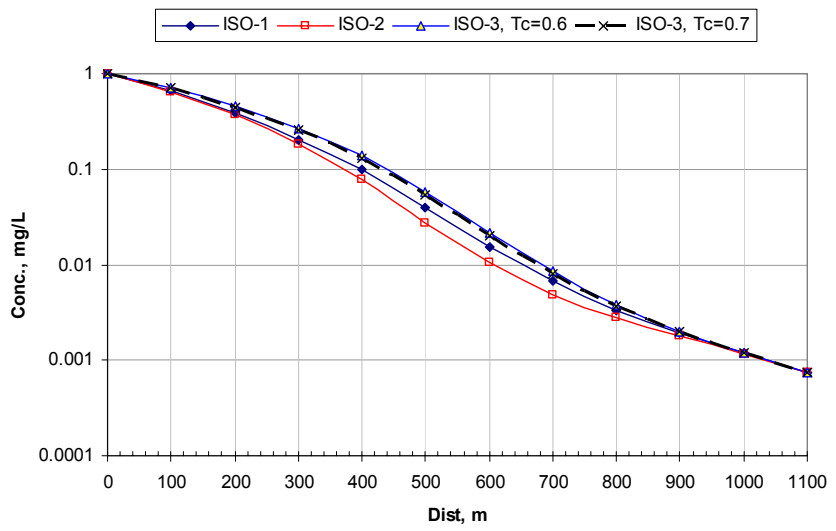

Figure 4: Steady-state VOC plume concentration profiles for the linear (ISO-1), non-linear (ISO-2), and plant toxicity (ISO-3) plant uptake models for the PCE field site. 


\subsection{Field-based simulations}

The tetrachloroethene (PCE) plume described in Struckhoff et al. [7] is simulated in fig. 4. The TSCF value is set at 0.755 based on the PCE data collected in the groundwater and poplar tree xylem. The recorded field and lab results for PCE uptake showed that the most realistic simulation is found by using the non-linear direct uptake model $(\mathrm{ISO}=2)$ with $\mathrm{N}=0.787$. The simulation of PCE uptake using the plant toxicity-based direct uptake model $(\mathrm{ISO}=3)$ is dependent on the plant maximum concentration capacity $\left(T_{c}\right)$. This factor ranges from $0-0.8$; however, the $\mathrm{ISO}=3$ simulation option is best suited for simulating sites with relatively high solute concentrations. In this case, $T_{c}$ is assumed equal to 0.6 . The higher the value of $T_{c}$, the closer the results to the linear direct uptake model $(\mathrm{ISO}=1)$.

\section{Conclusions}

A solute transport model was developed to study fate and transport of VOCs in groundwater subject to the presence of vegetation. The mathematical model was solved with a finite difference-based algorithm using the SEAM3D code and adding a new module (SEAM3D-PUP). While the translocation and volatilization of contaminants in the plant is not explicitly addressed, this study demonstrates the usefulness of numerical groundwater modelling in addressing several issues pertaining to the design or evaluation of a system of phreatophytic plants. The model has application at phytoremediation sites for evaluating or designing a containment system with respect to factors such as tree planting density, groundwater flow rate, seasonal effects, etc. The study suggests the need to integrate field measurements with computational modelling to minimize uncertainty.

\section{References}

[1] Schnoor, J. L., Phytoremediation of Soil and Groundwater. Ground-Water Remediation Technologies Analysis Center Report TE-02-01, 37 p., 2002.

[2] Schnoor, J. L., Light, L. A., McCutcheon, S.C., Wolfe, N.L. \& Carreira, L.H., Phytoremediation of organic and nutrient contaminants. Environmental Science \& Technology, 29(7), pp. 318A-323A, 1995.

[3] Newman, L.A., Strand, S.E., Choe, N., Duffy, J., Ekuan, G., Ruszaj, M., Shurtleff, B.B., Wilmoth, J., Heilman, P. \& Gordon, M.P., Uptake and Biotransformation of Trichloroethylene by Hybrid Poplars. Environmental Science \& Technology, 31(4), pp. 1062-1067, 1997.

[4] Burken, J. G. \& Schnoor, J. L., Predictive relationships for uptake of organic contaminants by hybrid poplar trees. Environmental Science \& Technology, 32(21), 3379-3385, 1998.

[5] Vroblesky, D. A., Nietch, C. T. \& Morris, J.T., Chlorinated Ethenes from Groundwater in Tree Trunks. Environmental Science \& Technology, 33(3), pp. 510-515, 1999. 
[6] Ma, X. \& Burken, J., VOCs Fate and Partitioning in Vegetation: Use of Tree Cores in Groundwater Analysis. Environmental Science \& Technology, 36(21), pp. 4663-4668, 2002.

[7] Struckhoff, C. G., Burken, J.G. \& Schumacher, J.G., Vapor-Phase Exchange of Perchloroethene between Soil and Plants. Environmental Science \& Technology, 39(6), pp. 1563-1568, 2005.

[8] Dietz, A.C. \& Schnoor, J. L., Advances in phytoremediation. Environmental Health Perspectives, 109(S1), pp. 163-168, 2001.

[9] Waddill, D.W. \& Widdowson, M.A., Three-dimensional model for subsurface transport and biodegradation. ASCE Journal of Environmental Engineering, 124(4), 336-344, 1998.

[10] Waddill, D.W. \& Widdowson, M.A., SEAM3D: A Numerical Model for Three-Dimensional Solute Transport and Sequential Electron AcceptorBased Biodegradation in Groundwater. U.S. Army Engineer Research and Development Center Technical Report ERDC/EL TR-00-X, 89 p., 2000. 